\title{
Genotype Syntactic Study of Vernacular Houses in Biskra City
}

\author{
Rihane Barkat ${ }^{1} \odot$, Yassine Bada ${ }^{2} \odot$, Yasemin Ince Guney ${ }^{3} \odot$ \\ ${ }_{1}^{1}$ PhD student, Lacomofa Lab,Department of Architecture,Biskra University, Biskra, Algeria. (Principal contact for editorial \\ correspondence),Email: rihane.barkat@univ-biskra.dz \\ 2Prof. Dr., Lacomofa Lab,Department of Architecture,Biskra University, Biskra, Algeria. Email: yassinebada@yahoo.fr \\ ${ }^{3}$ Assoc. Prof. Dr, Faculty of Architecture, Balikesir University, Balikesir, Turkey. Email: yasemince.guney@gmail.com
}

\section{Abstract \\ Purpose}

This paper provides an analysis of the vernacular houses of the city of Biskra, in the north-eastern Algerian Sahara. The aim is to examine the underlying genotype of the spatial configuration of the city's vernacular house plans and to consider the parameters that influence the domestic arrangement and phenotypic aspects of the house layout.

\section{Design/Methodology/Approach}

The investigation relied on space syntax method, by using j-graph (justified graph) analysis known as Gamma analysis to examine the functional spaces of a series of fifteen vernacular houses from three neighbourhoods (Bab Dareb, Mcid and Guaddach). And by using A-graph software to calculate syntactic properties such as MD, by obtaining RA, BDF and SLR, of the houses' spatial configurations, to detect similarities and differences in the sample. Moreover, to calculate the integration value (RRA) of each space of the same house to compare with those of others houses' space to determine the structure mode of the domestic interior.

\section{Findings}

The results suggest that there is an organising principle of spatial configuration as there are similarities between the socio-spatial patterns of vernacular houses in the city of Biskra, despite the disparate houses' interior spatial configuration.

\section{Research Limitations/Implications}

Most of the houses were in poor condition, which made the survey difficult. The present did not rely focus on people's use of internal space .e. behaviour mapping to detect the actual function of each space. Moreover, had this study taken houses with extremely different layouts and morphologies, and from distant times, would be a better case study to examine the undertaken topic.

\section{Originality/Value}

This study sheds light on the vernacular houses of the city of Biskra that has been extending since the Ottoman period to highlight the main underlying characteristics (genotype) using the theory of the syntax of space. These houses have a symbolic value and are considered as the architectural heritage of the city.

Keywords: Justified graph, privacy, space syntax, spatial configuration, the vernacular houses. 


\section{INTRODUCTION}

Vernacular architecture refers to traditional buildings that have been built using locally available materials and resources and that correspond to the climate and the basic expression of a community's cultural heritage. It has been accepted as a regional character for the society to which it belongs. Moreover, it is an authentic product built by people who are not experts in a specific place through knowledge shared over time. The study of vernacular architecture has become the study of the social and cultural impact of a specific place, and the architectural language of the people (Brown \& Maudlin, 2011).

Different studies have presented vernacular and modern houses as opposing architectures. Karim (1993) examined vernacular houses in the northern region of Algeria to identify the main features that can be used for the design of new houses, and searched for common aspects that can provide new models for modern housing. Bellal (2007) studied traditional M'Zabit houses by analysing the spatial configuration that is expressed through social events and studied the spatial interface between visitors and inhabitants. Widiastuti (2018) analysed the vernacular courtyard house in Kerala, and identified the main features using the topological method.

This study focuses on vernacular houses in the city of Biskra that represent the intellectual knowledge of the local community (Var, 2019) and to identify any significant correlation between the spatial configuration of the different houses. Three objectives are stated: to examine spatial organisation, to study social boundaries and to identify similarities in spatial layout. A comparative analysis of a sample of vernacular houses was carried out to uncover genotypic consistencies and underlying characteristics of the spatial configuration of the different phenotypes. Comparative analysis is an effective method for understanding the characteristics of the socio-spatial arrangements of these house types.

In addition, the theory of spatial syntax was used by applying the justified plan graph (JPG) method and mathematical calculations. The study examines the vernacular houses of the Ottoman period in the city of Biskra within the seven historical villages: M'cid, Bab Darb, Bab El Fath, Ras El Guerria, Korra, GueddachaandMedjniche. These seven villages, which are located in the southern part of the present city, still exist as neighbourhoods with most of the vernacular houses preserved. Three of these neighbourhoods were selected as case studies in the present paper.

\section{THE VERNACULAR HOUSES IN BISKRA CITY}

The vernacular housing in Biskra is characterised by its rural character and its perfect integration within the palm grove in the form of dispersed groupings (Figure 1). It has always tried to respond to various 
Figure 1.Picture showing the integration of vernacular houses inside their context. (Africa | "Rue dans la vieille ville" - Biskra || Vintage photographic print. ca. 1900)
Figure 2. The spatial configuration of a vernacularhouse (Aspatial organization of veernacularhouse; $\mathrm{B}-$ picture shows the rozna) (Authors,2020)

factors such as climate, religion, socio-cultural factors and the tradition of its community of builders (Saouli, 1989).
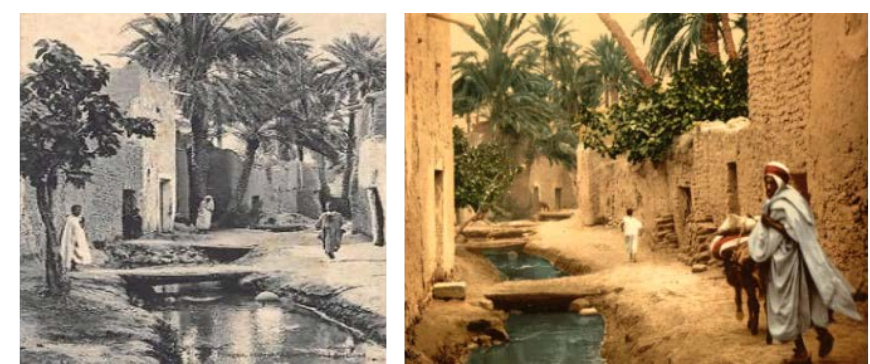

It is worth noting that the vernacular houses of Biskra city constitute an architectural heritage, and in particular they are sustainable constructions adapted to the climatic and environmental context. This fact is best manifested in the building materials and structural elements such as the "rozna" which is the opening in the ceiling of the central space, or the hall called "wasteddar" which can be manually operated (opened/closed) to regulate zenithal light and ventilation according to the daily and seasonal comfort requirement (Figure 2B). The spatial configuration of the vernacular houses was motivated by the existence of particular morphological features.

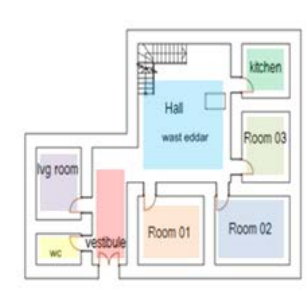

A-

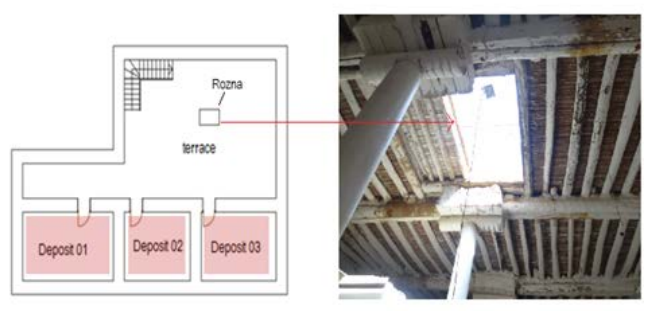

B-

The spatial organisation consists of three basic spaces: the hall (wasteddar), the vestibule (sguifa), and the room (bitt). The wasteddar is the most important feature of the spatial arrangement of vernacular houses.It is where daily activities take place: cooking, eating, watching TV, napping and resting. It is also where the family gathering could take place both during the day and at night (Adad \&Zerouala, 2002). The wasteddar is a covered space, considered the pivot of movement and distribution in the house, thus, the space through which the whole house is articulated. It is a space of regulation par excellence. According to the in-situ survey, today the functions of the wasteddar are reduced due to the addition of new spaces such as the kitchen, living room, guest room and bedrooms. This change refers to the evolution of social life and the opening up to other cultures.

A second important space is the vestibule (sguifa) which gives access to the house and is considered as a transitional and filtering space between the outer and inner space. This space also ensures the privacy of the inhabitants, especially the women. It acts as a screen preventing direct view of the interior of the house, thus allowing the door to be left open at all times during the day (Sriti, 2012). The rooms (bitt) are multifunctional spaces for a number of activities: sleeping (napping), 
resting, eating, studying, similar to Ottoman houses. Additional spaces include the bathroom (hamam), toilet (rmaya) and stable (couri).

\section{SPACE SYNTAX: THEORY AND METHOD}

This study focuses on the functional space analysis of the spatial configuration of a series of sample houses from the Ottoman period in the city of Biskra to discover the underlying genotype and examine whether cultural characteristics affected the spatial organisation of these vernacular houses (Vrusho \& Yunitsyna, 2016). The syntactic analysis conducted in this study consists of a comparative analysis of a sample of vernacular houses by describing the convex dimension, and examining the interaction between cultural characteristics and spatial organisation using the method of spatial syntax. The latter was developed by Hillier and Hanson (1984), identifying interior syntactic analysis as Gamma Analysis.

The analysis of the Justified Plan

Graph (JPG) is a technique representative of spatial configuration (Ostwald, 2011). The J-graph allows demonstrating the configurational properties of house plans, and provides a graphical and mathematical model to analyse the spatial configuration of buildings. It is a permeability structure where each functional space of the system is identified in terms of its relationship to every other space, showing the relational logic of the parts to the whole (Bellal, 2007). Each node in the graph refers to the functional or habitable spaces and the edge that links the spaces represents the connection between them.

In this work, the graph was used to represent the relationship between spaces in terms of permeability and access. This numerical method allowed illustrating house plans in the form of graphs. First, it focused on the abstraction of house plans into graphs and explored their configurational properties. Then, it relied on the AGRAPH software to carry out the different parameters considered in this analysis: the mean depth (MD), the real relative asymmetry (RRA), the base different factor (BDF), the space link= ratio (SLR) and the degree of spaceness.

The mean depth (MD) is used to distinguish how integrated or separated spaces are from each other. It also indicates how many steps one has to take to reach a specific space from the original space (the root) (Hillier \& Hanson, 1987). The real relative asymmetry (RRA) indicates the permeability of a system in quantitative terms, and is obtained by dividing the relative asymmetry (RA) of that node or graph by the given value $\mathrm{K}$ (the number of nodes). The base different factor (BDF) is used to provide a measure of the degree of differentiation between spaces in terms of integration, and quantifies the spread or degree of configurational differentiation between integration values. Hanson (1998: 30-31) reported that "the closer to 0 the difference factor, the more differentiated and structured the space; the closer to 1, the more homogenized the spaces or labels, to a point where all have equal 
integration values and hence no configurational differences exist between them".

The space link ratio (SLR) is used to assess the distributedness and nondistributedness properties of each space and the layout of the house. If there is only one non-intersecting route from one space to another in a system, it is said to be a non-distributed "a tree-like structure"; if there is more than one non-intersecting route for any two spaces in the system, it is called a distributed system. The degree of spaceness is useful in characterising the type of spaces in the system. Hillier (1996) differentiated four topological spaces: a-type, b-type, c-type and d-type. Using these parameters, this study aims to understand the underlying organisation and cultural characteristics that formed the layout of the vernacular houses, and to determine whether there is a cultural pattern (the genotype).

\section{CASE STUDY PRESENTATION}

The selected case studies are located in the old city. There are seven villages scattered to the south of the city which still exist today as neighbourhoods and still preserve most of their vernacular houses. The selection of houses was based on a survey of fifteen houses in three districts as the best preserved (Figure 3). Each house was given a code to facilitate the analysis: "HV" refers to a vernacular house. There are seven houses in Mcid: Hv01, Hv02, Hv03, Hv04, Hv06, Hv14 and Hv15; four houses in Gueddacha: Hv05, Hv07, Hv11 and Hv12; and four houses in the Bab Dareb district: Hv08, Hv09, Hv10, Hv13. The selection criteria

Figure 3. The three neighbourhoods. of these houses are based on their historical, temporal (date of construction), and architectural (structure, building materials, and architectural appearance) value where the residential fabric has adapted to its context.
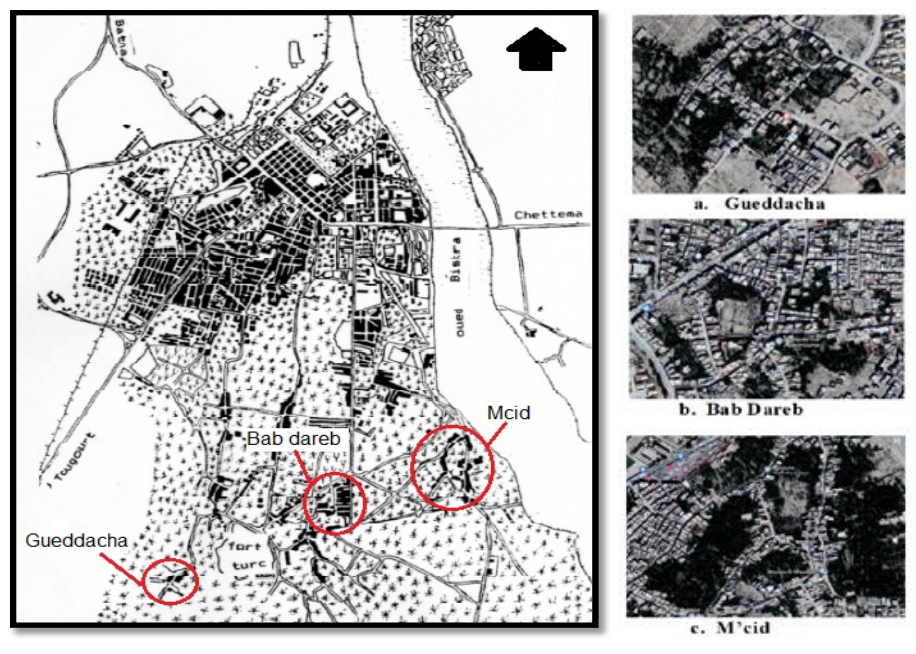

\section{ANALYTICAL PROCEDURES}

This study aims to identify the underlying genotype and to highlight the similarities and differences of a sample of houses in the city of Biskra. The justified graph analysis was used to specify the structural models 
based on the syntactic data (Guney \& Wineman, 2008). The justified graphs of these houses were embedded and analysed both by considering the exterior as a root and by excluding it. This methodology was adopted to examine different syntactic properties such as integration values (RA and RRA), depth and BDF. This syntactic data of the spatial pattern was analysed quantitatively using the A-graph program as a tool (McLane, 2013). The programme focuses on the conversion of house plans into graphs, in which the nodes represent the functional spaces and the lines represent the connection between the spaces.

These graphs were drawn according to the architectural plans of the houses, starting from the exterior (the root), and aligning the graph of all functional spaces according to their depth and distance from each other. Thus, although each node represents a functional space, several authors (Markus 1993; Hanson 1998; Dovey 1999) have chosen to consider the 'L-shaped' space as a single node (Ostwald, 2011). Whether the nature of the connection between spaces is a door or an opening, it is represented by a line. It only means that the connection exists. To discover the underlying characteristics (the genotype) a syntactic analysis was performed. The following steps were followed in this study:

a) First, the J-graphs were drawn for each of the fifteen houses using the exterior as a root to indicate the permeability sequence of the constituent spaces from the entrance to the interior of the house. The analysis of the spatial configuration focuses on the functional spaces with and without their exteriors.

b) Secondly, the graph measurement includes the mathematical calculations of the spatial configurations by analysing the different syntactic properties such as MD, by obtaining RA and BDF using the A-graph software, and by calculating RRA manually. The objective of this phase is to identify possible recurrences in the sample.

c) Thirdly, the integration values were calculated, using the Agraph program for each space of each house in the sample and comparing the integration value of each space with the other spaces of the same house. This allows the structuring mode of the domestic interior of the houses studied to be determined, while the classification of these integration values leads to a better understanding of the morphology of the spatial configuration for exploring the genotype in the sample.

d) Finally, the genotype groups were highlighted by using the space link ratio (SPL) indicator and the degree of spaceness. 


\section{CONFIGURATIONAL ANALYSIS AND GENOTYPE EXPLORATION}

A quantitative analysis was conducted using the spatial syntax method for the spatial configuration of the vernacular houses. The fifteen house plans were analysed with their graphs justified. Figure 4 shows the house plans. In this analysis, each functional space in the spatial organisation is treated as a cell, and is indicated by a circle, and the relationship between the cells is indicated by a line that refers to the transition (Erman, 2017). The graphs in Figure 4 have a consistent resemblance, and are deep from the original space. They were created using the exterior as a root and represent a tree-like structure (arborescent). The graphs have a symmetrical order in general and tend to lack in distributedness. Three graphs from the sample suggest a degree of permeability that is manifested by the presence of rings in the spatial configuration. This abstraction of the graphs distinguishes between the living space, the transition space and the other constituent spaces of the system.

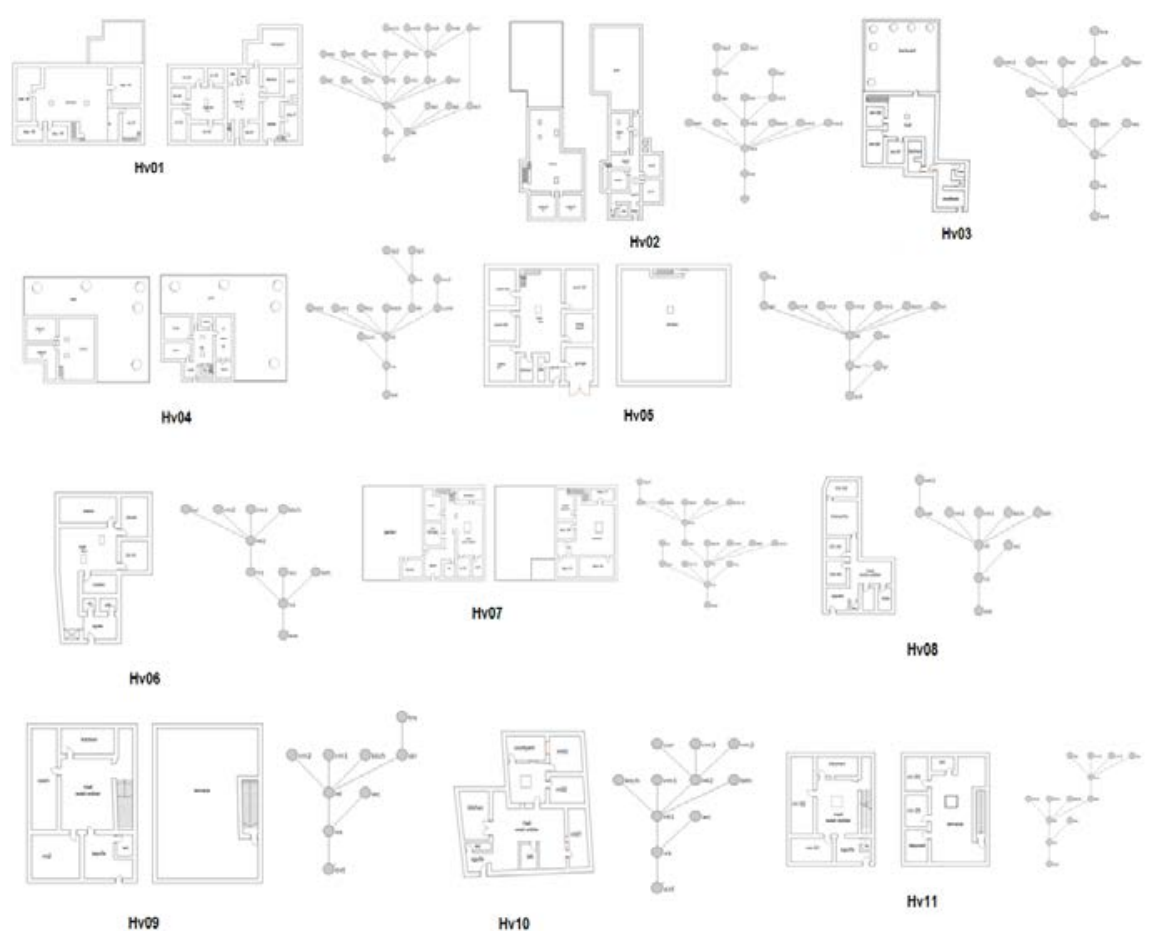

Fig 4. The house plans and their justified graphs.
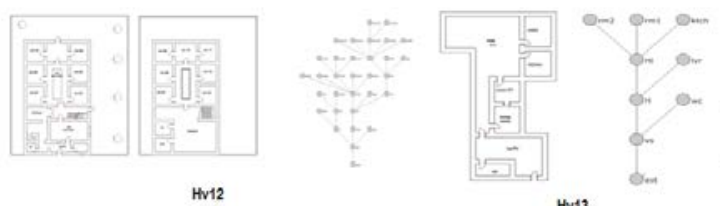

Hv13

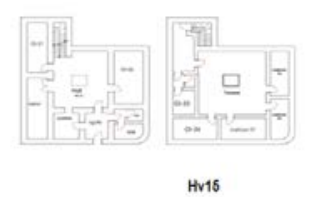


The spaces are classified by their relative depth starting from the root (exterior) space. In the first depth we observe that the vestibule (sguifa) is the shallowest space and the most important space in the composition of the spatial arrangement in vernacular houses. It is the topological btype space. The a-type space has the highest degree in the entire sample and is suitable for occupation where there is no movement of passage, unlike $c$ - and d-type spaces which have the lowest degree. The quantitative analysis was performed using the A-graph program with the following parameters: RRA, MD and BDF. These parameters were analysed using the exterior as a root and excluding it to understand the relationship between inhabitants - inhabitants and inhabitants - visitors. The data listed in Table 1 refers to the graphs in Figure 4.

Table 1: The syntactic data for sample of houses: MD: mean depth, SLR: space link ratio, BDF: base different factor (Authors,2021)

\begin{tabular}{|c|c|c|c|c|c|c|c|c|c|c|}
\hline \multirow[t]{2}{*}{$\begin{array}{c}\text { House } \\
\mathrm{N}^{\circ}\end{array}$} & \multirow[t]{2}{*}{ SLR } & \multirow[t]{2}{*}{ MD } & \multicolumn{3}{|c|}{$\begin{array}{l}\text { Integration (RRA) } \\
\text { (with exterior) }\end{array}$} & \multirow{2}{*}{$\begin{array}{l}\text { BDF } \\
\text { with } \\
\text { ext }\end{array}$} & \multicolumn{3}{|c|}{$\begin{array}{l}\text { Integration (RRA) } \\
\text { (without exterior) }\end{array}$} & \multirow{2}{*}{$\begin{array}{l}\text { BDF } \\
\text { with } \\
\text {-out } \\
\text { ext }\end{array}$} \\
\hline & & & $\min$ & mean & $\max$ & & $\min$ & mean & $\max$ & \\
\hline Hv01 & 1.08 & 3.03 & 0.36 & 0.89 & 1.17 & 0.88 & 0.36 & 0.89 & 1.17 & 0.86 \\
\hline Hv02 & 1.06 & 2.95 & 0.53 & 1.11 & 1.74 & 0.55 & 0.50 & 1.10 & 1.74 & 0.51 \\
\hline Hv03 & 1.00 & 2.84 & 0.57 & 1.15 & 1.82 & 0.45 & 0.49 & 1.10 & 0.59 & 0.41 \\
\hline Hv04 & 1.00 & 2.71 & 0.38 & 1.06 & 1.44 & 0.51 & 0.38 & 1.08 & 1.64 & 0.46 \\
\hline Hv05 & 1.09 & 2.12 & 0.22 & 0.84 & 1.13 & 0.42 & 0.18 & 0.87 & 1.27 & 0.37 \\
\hline Hv06 & 1.00 & 2.48 & 0.63 & 1.21 & 1.54 & 0.26 & 0.56 & 1.25 & 1.80 & 0.18 \\
\hline Hv07 & 1.05 & 3.21 & 0.65 & 1.13 & 1.67 & 0.67 & 0.59 & 1.15 & 1.77 & 0.62 \\
\hline Hv08 & 1.00 & 2.22 & 0.27 & 0.99 & 1.54 & 0.32 & 0.22 & 1.00 & 1.57 & 0.27 \\
\hline Hv09 & 1.00 & 2.22 & 0.33 & 1.10 & 1.23 & 0.59 & 0.29 & 1.12 & 1.74 & 0.18 \\
\hline Hv10 & 1.00 & 2.40 & 0.37 & 1.05 & 1.43 & 0.37 & 0.36 & 1.05 & 1.27 & 0.28 \\
\hline Hv11 & 1.00 & 2.82 & 0.60 & 1.20 & 1.59 & 0.44 & 0.63 & 1.20 & 1.79 & 0.35 \\
\hline Hv12 & 1.00 & 4.71 & 0.76 & 1.42 & 2.10 & 0.95 & 0.77 & 1.43 & 1.87 & 0.93 \\
\hline Hv13 & 1.00 & 2.38 & 0.56 & 1.25 & 1.69 & 0.19 & 0.58 & 1.27 & 2.03 & 0.07 \\
\hline Hv14 & 1.00 & 2.80 & 0.48 & 1.12 & 1.54 & 0.51 & 0.49 & 1.15 & 1.54 & 0.46 \\
\hline Hv15 & 1.05 & 3.37 & 0.71 & 1.25 & 1.61 & 0.65 & 0.68 & 1.25 & 1.74 & 0.60 \\
\hline Total & - & 2.81 & 0.49 & 1.11 & 1.54 & 0.51 & 0.47 & 1.12 & 1.45 & 0.43 \\
\hline
\end{tabular}

The depth: represents the number of spaces we have to pass to move from one particular space to another in the system (Mustafa \& Sanusi 2010). The total mean depth of all the systems is 2.81 , which signifies that the system is shallow from the exterior. House Hv12 has the highest mean depth value (4.71). The mean depth refers to the increase in the number of spaces that constitute the system (31 spaces) and the decrease in the number of steps that need to be taken to reach a particular space. As shown by J-graph, the rooms are the deepest spaces in the spatial arrangement and the transitional spaces such as the vestibule (sguifa) and halls are the shallowest spaces from the root. House Hv5 has the lowest mean depth value (2.12) and contains 10 spaces; it is shallow from the exterior, and has the lowest number of steps to move around the house. However, the number of spaces is not proportional to the mean depth, while houses Hv3 and Hv4 have an equal number of spaces 14, with mean depths of 2.84 and 2.71, respectively. House Hv1 has a mean depth of 3.03 and 25 spaces; house Hv7 has a mean depth of 3.21 and 19 spaces. From these results, it can 
be noted that the houses are deep from the exterior, which indicates the position of the internal spaces from the exterior world and the public's point of view.

The integration value (RRA): refers to how connected and closed a space is to all other different types of spaces. In other words, it describes the extent to which the space is accessible from all spaces in the system. The integration values give a quantitative indication of the permeability of the system (Guney \& Wineman, 2008) and the degree of overall integration of the building. The lower the integration value and closer to 0 , the more integrated the system is and the more connected the spaces are to each other in the system. Thus, the higher value of integration which tends towards 1 and above means the segregation of the system. Table 1 lists the integration values (RRA) of all houses. There are two integration values presented in the Table 1: one with the exterior being part of the system and the other when it is not. The purpose of using the two integration values (RRA) with and without the exterior is to see how the system has treated the exterior and its significance on the entire house configuration.

The data show that the integration values (RRA) for the entire sample are 1.11 when the exterior is included, and 1.13 when it is not. Therefore, the values indicate that the sample is more segregated. The house Hv11 has an equal integration value with and without the exterior of 1.20 . It is noteworthy that when the exterior is included, the houses Hv2, Hv3, Hv4, Hv5, Hv6, Hv7, Hv9, Hv10, Hv11, Hv12, Hv13, Hv14, Hv15 become more segregated with values of 1.11, 1. 15, 1.06, 1.21, $1.13,1.10,1.05,1.20,1.42,1.25,1.12,1.25$ respectively. In this case, the houses become more closed, are described as introverted houses (Guney \& Wineman, 2008). And the houses Hv1, Hv5, Hv8, become more integrated with values of $0.89,0.84,0.99$. The most integrated house is Hv5 (0.84) with exterior ( 0.87 when the exterior is not included). And the most segregated house is Hv12 with an integration value of 1.42 (1.43 without exterior). Thus, it can be noted that when the system is more segregated, the houses tend to lack permeability and are less accessible, in addition to controlling the need for privacy to regulate interpersonal interactions.

The base different factor (BDF): is used to provide a measure of the degree of differentiation between the spaces in terms of integration (Mustafa, 2016). When the value of BDF tends towards 0, it indicates a strong differentiation and the system needs to be more structured. When the value tends towards 1, it means that there is a small difference between the spaces. Table 1 provides the basic syntactic data for each $h$ ouse. In the sample, the lowest BDF is in house Hv13 with a value of 0.19 and then in house Hv6 with a value of 0.26 , which indicates strong differentiation and structuring of these two houses. Houses Hv1, Hv12 have the highest BDF values (0.88 and 0.95 , respectively), which indicate weak differences. The other houses have a mean value that 
varies between 0.32 and 0.67 . It should be noted that the sample of houses in general has strong functional differences between the constituent spaces of the interior spaces.

From the analysis of these parameters, a careful observation of the data in Table 1 reveals certain similarities in the spatial configuration of the sample. Hillier and Hanson (1987) stated that a cultural pattern can exist if a configurational consistency occurs (Boutabba et al., 2020). At this stage, we are not in a position to talk about the genotype, but only about the way in which the layout of the houses is structured. To define the genotype, other syntactic parameters are highlighted in this study, expressed by the order of integration. The domestic interior of the house layout was analysed; each space in each house was compared to other spaces in the same house in the sample according to its degree of integration (RRA). This ordering could provide a better understanding of the morphology of the spatial configuration. If this ordering remains in a consistent order across a sample, then there is evidence of a cultural pattern (genotype). Table 2 presents the order of integration of the houses.

Table 2 presents the ranking order of the integration values (relative asymmetry RA) of all the interior "functional spaces" in each house. The ranking order, from the most integrated space to the most separated space, shows that the hall $(\mathrm{Hl})$ is the most integrated space in every house in the entire sample, except for houses Hv12 where the intermediate space (I) is the most integrated space, and house Hv13 where the corridor $(\mathrm{H})$ is the most integrated space. The order of integration shows that the hall $(\mathrm{Hl})$, the vestibule $(\mathrm{V})$, the staircase (str) and the terrace (trs) are in the first order in all houses, while they are considered as transitional spaces of the topological b-type space. The vestibule is the space that connects directly to the exterior; it is the filter between the external and internal domestic space, and it is connected directly to the hall (wasteddar) or to a corridor in some cases. The hall provides access to all the spaces in the house and is considered the most integrated space in all but two of the houses in the sample. The bedrooms, bathroom, toilet, storage spaces are the most separated spaces in the whole sample which all belong to the topological a-type space.

Table 2: The order of integration of living function each of house (Authors, 2021)

\begin{tabular}{|c|c|c|c|}
\hline $\mathrm{N}^{\circ}$ & RA: mean & Houses & Order of integration (with exterior) \\
\hline 01 & 0.17 & Hv01 & $\begin{array}{l}\mathrm{Hl} 1<\mathrm{Hl} 2=\mathrm{str}=\mathrm{stb}<\mathrm{vs}<\mathrm{wc}=\mathrm{bth}=\mathrm{rm} 1=\mathrm{ktch}=\mathrm{byr}=\mathrm{trs}=\mathrm{str} 2< \\
\text { ext=rm7 }<\mathrm{rm} 3=\mathrm{rm} 2=\mathrm{rm} 4=\mathrm{rm} 5=\mathrm{rm} 6=\mathrm{dp} 1=\mathrm{dp} 2<\mathrm{rm} 9=\mathrm{rm} \\
8=\mathrm{rm} 10=\mathrm{rm} 11\end{array}$ \\
\hline 02 & 0.27 & Hv02 & $\begin{array}{l}\mathrm{Hl} 1=\mathrm{Hl} 2<\mathrm{str}<\mathrm{Hl} 3<\mathrm{lvr}<\mathrm{ktch}=\mathrm{rm} 1=\mathrm{wc}=\mathrm{bth}=\mathrm{rm} 2<\mathrm{trs}<\mathrm{byr} \\
<\mathrm{ext}<\mathrm{dp} 1=\mathrm{dp} 2\end{array}$ \\
\hline 03 & 0.30 & Hv03 & $\mathrm{Hl} 1<\mathrm{Hl} 2<\mathrm{In}<\mathrm{ktch}=\mathrm{lvr}=\mathrm{rm} 1=$ byr $=\mathrm{rm} 2<\mathrm{vs}<\mathrm{bth}<\mathrm{trs}<$ ext \\
\hline 04 & 0.28 & Hv04 & $\begin{array}{l}\mathrm{Hl}<\mathrm{str}<\mathrm{vs}<\mathrm{lvr}<\mathrm{ktch}=\text { byr }=\mathrm{rm} 1=\mathrm{rm} 2<\operatorname{trs}<\mathrm{grm}=\mathrm{ext}<\mathrm{rm} 3< \\
\text { dp1=dp2 }\end{array}$ \\
\hline
\end{tabular}




\begin{tabular}{|c|c|c|c|}
\hline 05 & 0.30 & Hv05 & $\mathrm{Hl}<\mathrm{vs}<\mathrm{rm} 2=\mathrm{rm} 1=\mathrm{rm} 3=\mathrm{rm} 4=\mathrm{ktch}=\mathrm{lvr}<\mathrm{gr}=\mathrm{ext}<\mathrm{wc}$ \\
\hline 06 & 0.25 & Hv06 & $\mathrm{Hl}=\mathrm{Hl} 2<\mathrm{vs}<\mathrm{ktch}=\mathrm{rm} 1=\mathrm{rm} 2=\mathrm{lvr}<\mathrm{ext}=\mathrm{bth}=\mathrm{wc}$ \\
\hline 07 & 0.34 & Hv07 & $\begin{array}{l}\mathrm{Hl}<\mathrm{str}<\mathrm{vs}<\mathrm{trs}<\mathrm{rm} 2=\mathrm{ktch}=\mathrm{rm} 1=\mathrm{bth}<\mathrm{byr}=\mathrm{I}<\mathrm{ext}=\mathrm{wc}=\mathrm{grm} \\
=\mathrm{dp} 3<\mathrm{dp} 2=\mathrm{dp} 1=\mathrm{kch} \text { tr }<\mathrm{cr}=\mathrm{dp} 4\end{array}$ \\
\hline 08 & 0.24 & Hv08 & $\mathrm{Hl}<\mathrm{vs}<$ cor $<\mathrm{rm} 1=\mathrm{ktch}=\mathrm{bth}=\mathrm{rm} 2<\mathrm{ext}=\mathrm{wc}<\mathrm{rm} 3$ \\
\hline 09 & 0.39 & Hv09 & $\mathrm{Hl}<\mathrm{vS}<\mathrm{str}<\mathrm{rm} 1=\mathrm{ktch}=\mathrm{rm} 2<\mathrm{ext}<\mathrm{trs}$ \\
\hline 10 & 0.30 & Hv10 & $\mathrm{Hl}<\mathrm{Hl} 2<\mathrm{vs}<\mathrm{ktch}=\mathrm{bth}=\mathrm{rm} 1<\mathrm{rm} 2=\mathrm{rm} 3=$ cor $<\mathrm{wc}=\mathrm{ext}$ \\
\hline 11 & 0.31 & Hv11 & $\begin{array}{l}\mathrm{Hl}<\mathrm{str}<\operatorname{trs}<\mathrm{vs}<\mathrm{rm} 1=\mathrm{ktch}=\mathrm{rm} 2<\mathrm{dp}=\mathrm{rm} 4=\mathrm{rm} 3=\mathrm{wc} 2<\mathrm{wc}= \\
\text { ext }\end{array}$ \\
\hline 12 & 0.33 & Hv12 & $\begin{array}{l}\mathrm{I} 2<\mathrm{str}<\mathrm{Hl} 1=\mathrm{Hl} 2<\mathrm{trs}<\mathrm{vs}=\mathrm{byr}<\mathrm{h}<\mathrm{rm} 3<\mathrm{rm} 2=\mathrm{rm} 4=\mathrm{rm} 1=\mathrm{r} \\
\mathrm{m} 5<\mathrm{bth}=\mathrm{dp}<\mathrm{I}<\mathrm{ext}=\mathrm{dp} 1=\mathrm{rm} 10<\mathrm{rm} 6=\mathrm{rm} 5=\mathrm{rm} 7=\mathrm{rm} 9=\mathrm{r} \\
\mathrm{m} 11=\mathrm{rm} 8=\mathrm{rm} 12<\mathrm{I} 3=\mathrm{bth}<\mathrm{rm} 14=\mathrm{rm} 13<\mathrm{ktch}=\mathrm{wc}\end{array}$ \\
\hline 13 & 0.29 & Hv13 & $\mathrm{H}<\mathrm{Hl}<\mathrm{vS}<\mathrm{lvr}<\mathrm{rm} 1=\mathrm{ktch}=\mathrm{rm} 2<\mathrm{wc}=\mathrm{ext}$ \\
\hline 14 & 0.37 & Hv14 & $\begin{array}{l}\mathrm{Hl}<\mathrm{str}<\mathrm{I}<\mathrm{trs}<\mathrm{rm} 2=\mathrm{rm} 3=\mathrm{rm} 1=\mathrm{ktch}<\mathrm{ext}=\mathrm{grm}=\mathrm{wc}<\mathrm{dp} 1=\mathrm{d} \\
\mathrm{p} 2=\mathrm{dp} 3\end{array}$ \\
\hline 15 & 0.26 & Hv15 & $\begin{array}{l}\mathrm{Hl}=\mathrm{str}<\mathrm{I} 2<\mathrm{trs}<\mathrm{I} 3<\mathrm{vs}<\mathrm{ktch}<\mathrm{rm} 2=\mathrm{lvr}=\mathrm{rm} 1<\mathrm{rm} 4=\mathrm{dp} 1=\mathrm{dp} \\
2=\mathrm{dp} 3<\mathrm{rm} 3=\mathrm{wc}<\text { ext }\end{array}$ \\
\hline
\end{tabular}

The results in Table 2 show a clear recurrence in the mode of spatial structuring as most of the houses are structured around the hall (wasteddar) in the sample; this is the genotype, except for Hv12 which is structured around the intermediate space (I) and the house Hv13 is structured around the corridor $(\mathrm{H})$. Moreover, the results demonstrate the existence of underlying characteristics in the spatial pattern of the sample, as Hillier and Hanson (1987) state: "the cultural pattern exists". Recurrence in syntactic properties may be an indication of genotype.

\section{DEFINITION OF GENOTYPE GROUPS USING THE DEGREE OF SPACENESS AND THE SPACE LINK RATIO}

The degree of spaceness: the JPG technique allows the type of space in the system to be categorised. Hillier (1996) distinguished four topological spaces: a-type, which has one link, b-type, which connects to two or more spaces, c-type, which lies on a ring and has more than one connection, and d-type, which lies on at least two rings and has more than two connections. Private (bedrooms), social (living room) and service (kitchen and bathrooms) spaces are a-type spaces; transition spaces (hall, corridor, staircase) are b-type spaces. The graphs in Figure 4 show a tree structure characterised by the existence of topological atype space, which is the appropriate space for occupancy, and topological b-type spaces, which are transition spaces, suggesting that there is no mobility choice in the system. Table 3 presents the calculation of the degree of a-ness, b-ness, c-ness and d-ness. They give an insight into the use of space in the spatial configuration.

From these results, it can be noticed that a-type spaces represent the highest percentage in the whole sample (63\%). This type includes each of the private, social and service spaces such as bedrooms, kitchen, bathroom, storage, and the living space where daily activities take place. The a-type space creates segregation as a result of the increase in depth. While the transition area such as halls, corridors, vestibules (sguifa), 
terrace, and stairs are the transitional b-type spaces represent $30 \%$ of the sample suggesting that there is no choice of movement to and from this space. These are pass-through spaces, while all houses have an average percentage of b-type space. The c-type spaces represent $20 \%$ of the sample and fall in a ring suggesting a choice of movement around the house as in houses Hv1, Hv2, Hv5, Hv7, Hv15. The d-type spaces have the lowest degree (8\%) of the sample offer alternative of movement when moving around the house as in the case of house Hv1.

Table 3: Degree of space-ness indicator of the space type (Authors,2021)

\begin{tabular}{|c|c|c|c|c|}
\hline \multirow{2}{*}{ Houses } & \multicolumn{4}{|c|}{ The degree of spaceness (space type) } \\
\cline { 2 - 5 } & a-ness & b-ness & c-ness & d-ness \\
\hline $\mathrm{Hv}_{1}$ & 0.66 & 0.04 & 0.24 & 0.08 \\
\hline $\mathrm{Hv}_{2}$ & 0.53 & 0.28 & 0.18 & 0.00 \\
\hline $\mathrm{Hv}_{3}$ & 0.61 & 0.41 & 0.00 & 0.00 \\
\hline $\mathrm{Hv}_{4}$ & 0.61 & 0.33 & 0.00 & 0.00 \\
\hline $\mathrm{Hv}_{5}$ & 0.70 & 0.11 & 0.27 & 0.00 \\
\hline $\mathrm{Hv}_{6}$ & 0.66 & 0.37 & 0.00 & 0.00 \\
\hline $\mathrm{Hv}_{7}$ & 0.61 & 0.27 & 0.15 & 0.00 \\
\hline $\mathrm{Hv}_{8}$ & 0.66 & 0.37 & 0.00 & 0.00 \\
\hline $\mathrm{Hv}_{9}$ & 0.62 & 0.42 & 0.00 & 0.00 \\
\hline $\mathrm{Hv}_{10}$ & 0.70 & 0.33 & 0.00 & 0.00 \\
\hline $\mathrm{Hv}_{11}$ & 0.66 & 0.36 & 0.00 & 0.00 \\
\hline $\mathrm{Hv}_{12}$ & 0.64 & 0.30 & 0.00 & 0.00 \\
\hline $\mathrm{Hv}_{13}$ & 0.62 & 0.42 & 0.00 & 0.00 \\
\hline $\mathrm{Hv}_{14}$ & 0.69 & 0.33 & 0.00 & 0.00 \\
\hline $\mathrm{Hv}_{15}$ & 0.58 & 0.25 & 0.16 & 0.00 \\
\hline $\mathrm{T}_{0}{ }_{2}$ & 0.63 & 0.30 & 0.20 & 0.08 \\
\hline
\end{tabular}

According to the data of the space-ness indicator of the sample in Table 3 , the a-type space has the highest degree in all houses (63\%), while the d-type has the lowest degree (8\%). House Hv1 is the only house in the sample that has all four topological spaces with the following values: aness 0.66 , b-ness 0.04 , c-ness 0.24 , d-ness 0.08 . Four houses have three topological spaces (a-, b-, and c-ness): Hv2, Hv5, Hv7, Hv15 with the following values: a-ness $0.53,0.70,0.61,0.58$, respectively; b-ness 0.28 , $0.110 .27,0.25$, respectively; c-ness $0.18,0.27,0.15,0.26$, respectively. Ten houses have two topological spaces (a and b-ness): Hv3, Hv4, Hv6, Hv8, Hv9, Hv10, Hv11, Hv12, Hv13, Hv14, with the values: a-ness 0.61, $0.61,0.66,0.620 .70,0.66,0.64$, respectively; b-ness $0.41,0.33,0.37$, $0.37,0.42,0.33,0.36,0.30,0.42$

, 0.33 , respectively. Thus, in houses characterised by the high value of atype spaces, there is no "through" circulation, and in b-type spaces which are transition spaces open directly onto a-type space. The results reveal the presence of a-type and b-type spaces in $100 \%$ of the sample, which refer to private, social and service spaces. The private and social spaces represent the separate spaces in the system such as bedrooms, halls, living room and guest room. There is no penetration into these spaces which provide a high degree of control due to their nature as spaces for specific functions such as sleeping, resting and eating.

The space link ratio (SLR): this indicator is used to assess the distributedness and non-distributedness properties of each space and 
the arrangement of houses; if there is only one non-intersecting route from one space to another in a system, it is called a non-distribution "tree-like structure". If there is more than one non-intersecting route for any two spaces in the system, it is called a distributed system. According to the data, ten houses Hv3, Hv4, Hv6, Hv8, Hv9, Hv10, Hv11, Hv12, Hv13 and Hv14 of the entire sample have a value of 1.00, which refers to non-distributedness, while the system offers a guided path with no alternative movement. The houses Hv1, Hv2, Hv5, Hv7 and Hv15 have values of $1.08,1.06,1.09,1.05,1.05$ respectively. The results indicate that these houses have a distributedness system. Thus, the system gives an alternative of movement and circulation within the house. The distributedness reflects the existence of rings in the systems, and more than one intersecting path from the root to other spaces in the system which indicates the flexibility of movement.

Based on the graphs, three houses, Hv2, Hv7 and Hv15, have internal rings that are shaped around the transitional spaces of the c-type space which are "through spaces". House Hv1 has two rings, one external and one internal. House Hv5 has an external ring, shaped around the vestibule, exterior, stable and garage, providing alternative access from the exterior. In general, the J-graphs in the sample (Figure4) describe a symmetrical configuration and have arborescent visual configurations "tree-like structures", which are deep, and define a hierarchical control within the house. The graphs have a guided path from the exterior (root space) from the point of view of the "visitor", relative to the first space (vestibule) entered from the exterior to the guest room (receiving space), unlike the inhabitants who used alternative paths to move around the house. Hillier and Hanson (1984) argued that there are two types of social relationships detected in J-graphs; firstly, the relationship between inhabitants (kinship relationships), and secondly the relationship between inhabitants and visitors.

By analysing the degree of space-ness and the space link ratio (SLR) of the sample, it can be noted that the results are consistent. Two groups of genotypes are identified; the dominant group is composed of ten houses and the minor group is composed of five houses (Table 4). The results are listed in Table 4, where a clear recurrence is noticed in both groups. The dominant group I shows a tree structure with no alternative routes offering a degree of control within the houses, while the minor group II shows a ring-shaped spatial configuration that offers alternative movement within a part of the house. The different base factor was calculated for each house to check the strength and homogeneity of the groups to report the genotype. The first group I shares a significant recurrence and shows a BDF value fluctuating between 0.19 and 0.59 for the houses Hv3, Hv4, Hv6, Hv8, Hv9, Hv10, Hv11, Hv13 and Hv14. These results show a strong functional differentiation of the house layouts. The house Hv12 shows a small difference. The minor group II shows that the house layouts have more than one circulation alternative and a strong functional differentiation (Boutabba et al., 2020). The analysis of the 
layout of the houses suggests that there are two types of houses identified in the sample, with two underlying functional spatial genotypes in evidence.

Table 4: Identification of genotype groups using SLR and BDF (Authors,2021) a- The dominant genotype I b- The minor genotype II

\begin{tabular}{|c|c|c|}
\hline Houses & SLR & BDF \\
\hline $\mathrm{Hv}_{3}$ & 1.00 & 0.45 \\
\hline $\mathrm{Hv}_{4}$ & 1.00 & 0.51 \\
\hline $\mathrm{Hv}_{6}$ & 1.00 & 0.26 \\
\hline $\mathrm{H}_{8}$ & 1.00 & 0.32 \\
\hline $\mathrm{Hv}_{9}$ & 1.00 & 0.59 \\
\hline $\mathrm{Hv}_{10}$ & 1.00 & 0.37 \\
\hline $\mathrm{Hv}_{11}$ & 1.00 & 0.44 \\
\hline $\mathrm{Hv}_{12}$ & 1.00 & 0.95 \\
\hline $\mathrm{Hv}_{13}$ & 1.00 & 0.19 \\
\hline $\mathrm{Hv}_{14}$ & 1.00 & 0.51 \\
\hline
\end{tabular}

\begin{tabular}{|c|c|c|}
\hline Houses & SLR & BDF \\
\hline $\mathrm{Hv}_{1}$ & 1.08 & 0.88 \\
\hline $\mathrm{Hv}_{2}$ & 1.06 & 0.55 \\
\hline $\mathrm{Hv}_{5}$ & 1.09 & 0.42 \\
\hline $\mathrm{Hv}_{7}$ & 1.05 & 0.67 \\
\hline $\mathrm{Hv}_{15}$ & 1.05 & 0.65 \\
\hline
\end{tabular}

\section{DISCUSSION AND CONCLUSION}

This study examined the underlying characteristics of spatial organisation by comparing the functional spaces of fifteen vernacular houses located in the city of Biskra, north-eastern Algerian Sahara. The method of justified graph analysis allowed to identify their patterning. Regarding to the analysis of the different syntactic properties, the house plans share common characteristics; the spatial organisation of the houses is structured around transition spaces such as the hall (wasteddar) and the corridor. The wasteddar is the main central space of the vernacular house; it is a b-type topological space where most of the daily domestic activities take place; in terms of integration values, it is considered the most integrated space in the house plans. The vestibule (sguifa) is located at depth1 in all houses, it is shallow from the root space (exterior). Moreover, it is one of the specific spaces that characterize the vernacular house in Biskracity. It is the boundary between the exterior space and the interior space that provide visual privacy inside the house. The sguifa is the point of entry of visitors into the house, while access is regulated by socio-cultural rules. The bedrooms are the most segregated spaces, they are located at the end of the graphs; they are suitable for inhabitants who tend towards private use. It should be noted that the guest room is shallow from the exterior because it is specific for strangers.

Observation of the sample graphs shows a strong similarity between spatial configurations, while the results of the in-depth analysis show that the deeper one goes into the structure, the more private the spaces become, such as private spaces (bedrooms, storage spaces) and service spaces (kitchen, bathroom), while the transitional spaces (hall, vestibule, corridors) are the most integrated spaces in the houses, which provide a degree of control within the house (Table 2). House layouts become more segregated when the exterior is included in the analysis (1.11). However, for houses with weak relationships with the exterior 
space and classified as 'introverted houses', the exterior is always on the segregated side, when integration values are considered with the exterior.

The degree of integration of each space of a house from the sample is compared to the other spaces in the same house. The results show that the ranking order of the spaces in all houses is in a consistent order, and it can be said that a cultural pattern exists across the sample. Furthermore, the recurrence of certain structural characteristics (such as RRA, MD, BDF) in this sample is a strong indication of genotype. Therefore, the low BDF values of all houses refer to a strong functional differentiation of the house layout and indicate the strength of social relations. The hierarchy of spatial organisation of functional spaces in the houses shows that the inhabitants tend to favour privacy. From the space link ratio and spaceness that are used to refine the genotype, two groups are determined (Table 4). The dominant genotype I has a treelike configuration and a non-distributedness within the system, while the minor genotype II has a ring structure and a distributedness system that provides an alternative pathway within the system. Comparison of the BDF values of the two genotypes indicates that both groups have a high BDF, so the configuration tends to favour functional differentiation of spaces. It is important at this point to state that there are two genotypes.

The findings of this research indicate that the J-graphs of the case study houses are similar to each other and share the same basic characteristics of the configurational functions described as "genotypical signature". They structure the relationships between the residences, and control the boundaries between the internal spaces and the external world. Social and cultural factors are reflected in the spatial configuration of the sample, while there are two types of social relations, the first being the relationship between the inhabitants themselves and between the inhabitants and strangers. In conclusion, vernacular houses are regulated and controlled by socio-cultural factors, such as "intimacy", which is considered a vital and sacred rule to preserve family members. The quantitative approach used in this study assessed this characteristic in different spatial arrangements of houses. However, houses with extremely different layouts and morphologies, and from distant times, would be better cases to examine the topic undertaken by this study.

\section{ACKNOWLEDGEMENTS}

This study is based on the doctoral thesis of Barkat Rihane. Particular acknowledgements are addressed to Professor Bada Yassine and Professor Yasemin Ince Guney, for their valuable contributions.

\section{CONFLICT OF INTEREST}

No conflict of interest was declared by the authors. 


\section{FINANCIAL DISCLOSURE}

The authors declared that this study has received no financial support.

\section{ETHICS COMMITTEE APPROVAL}

Ethics committee approval was not required for this article.

\section{LEGAL PUBLIC/PRIVATE PERMISSIONS}

In this research, the necessary permissions were obtained from the relevant participants (individuals, institutions, and organizations) during the survey and in-depth interviews.

\section{REFERENCES}

Adad, \& Zerouala. (2002). Apprendre du passe cas du vieux Biskra. Sciences \& Technologie - $N^{\circ} 17,123-132$.

B Hillier, J Hanson, H. G. (1987). Ideas are in things: an application of the space syntax method to discovering house genotype. Environment and Planning B, 14, 363-385.

Bellal, T. (2007). Spatial Interface Between Inhabitants and Visitors in M'zab Houses. Proceedings, 6th International Space Syntax Symposium, Istanbul, 2007, 61.1-61.14.

Boutabba, H., Djemoui, B. S., \& Mili, M. (2020). Spatial logic of the neorural houses of the Msilien Guebla in Algeria. Urbanism. Architecture. Constructions.11(1):35-56

Brown, R., \& Maudlin, D. (2011). Concept of Vernacular Architecture. 340-355.

Dovey, Kim. 1999. Framing places: Mediating power in built form. London: Routledge.

Erman, 0. (2017). Analysis of the architectura space through the spatial neighborhood concept. Mekansal Komşuluk Kavramı Üzerinden Mimari Mekanin Analizi, Cukurova University Journal of the Faculty of Engineering and Architecture. 32(1). pp. 165- 176.

Guney, Y. I., \& Wineman, J. (2008). The evolving design of 20th-century apartments in Ankara. Environment and Planning B: Planning and Design, 35(4), 627-646. https://doi.org/10.1068/b3401

Hanson, J. 1998 Decoding Homes and Houses, Cambridge : Cambridge University Press.

Hillier B and Hanson J (1984) The Social Logic of Space. Cambridge: Cambridge University Press. https:/doi.org/978052133651.

Hillier, B. 1996 Space is the Machine, Cambridge : Cambridge University Press.

Karim, H. (1993). Vernacular housing forms in north Algeria. TDSR.(5)1. 65-74. 
Markus, Tom. 1993. Buildings and power. London: Routledge.

McLane, Y. (2013). Spatial contexts, permeability, and visibility in relation to learning experiences in contemporary academic architecture. Florida State University Libraries . http://diginole.lib.fsu.edu/etd.

Mustafa, F. A. (2016). Spatial Configuration and Functional Efficiency Of House Layouts. LAP.Erbil.

Mustafa, F. A., \& Sanusi, A. H. (2010). Using space syntax analysis in detecting privacy: a comparative study of traditional and modern house layouts in Erbil. The 2nd. International Seminar on Tropical EcoSettlements, 3-5 November .

Ostwald, M. J. (2011). The Mathematics of Spatial Configuration: Revisiting, Revising and Critiquing Justified Plan Graph Theory. Nexus Network Journal, 13(2), 445-470. https://doi.org/10.1007/s00004-0110075-3

Saouli, A.Z. (1989). The revival of traditional housing: The case of Biskra. (Doctoral dissertation), Institute of advanced architectural studies. University of York.

Sriti, L. (2012). Architecture domestique en devenir. Formes, usages et représentations Le cas du Biskra. université de Biskra.

Var, E. B. (2019). Influencing Factors for Spatial and Morphological Transformations of Vernacular Houses: In The Case of Trabzon, Turkey HOUSE \& HOME ' 17 / International Interdisciplinary Architecture and Urban Studies Conference LITERATURE, ARCHITECTURE AND URBAN SPAC. January.

Vrusho, B., \& Yunitsyna, A. (2016). Space syntax anaysis in the Albanian dwellings. X. SCIRES.https://doi.org/10.2423/i22394303vXnYppp.

Widiastuti, I. (2018). Typology Study of Vernacular Courtyard-House in Kerala, South India. Jurnal Sosioteknologi, 17(3), 365-372. https://doi.org/10.5614/sostek.itbj.2018.17.3.4

\section{Resume}

Rihane Barkat graduated from Biskra university, Department of Architecture in 2015. She obtained her master's degree in urban projects and PhD (2015) degree on Habitat and Sustainable cities. Her research interest is Domestic Architecture.

Yassine Bada is a professor at the department of architecture, university of Biskra where he has been a faculty member since1990. His research interests focus spacemorphology/people's behavior relationship, with particular reference to Space Syntax as theory and analysis method.

Yasemin Ince Guney received Bachelors and M.Sc. in Architecture from Middle East Technical University, M.Sc. in Architecture from University of Nebraska-Lincoln, and PhD. in Architecture from University of Michigan, USA. She has taught at Lawrence Technological University, Southfield, Michigan, Eastern Mediterrenean University North Cyprus and teaching currently at Balikesir University. 